РАЗРАБОТКА ТЕХНОЛОГИИ СОУСОВ С ДОБАВКОЙ РАСТИТЕЛЬНОГО ПРОИСХОЖДЕНИЯ С ПОВЫШЕННОЙ ПИЩЕВОЙ ЦЕННОСТЬЮ

\author{
А.Д. Тошев, Н.Д. Журавлева \\ Южно-Уральский государственный университет, г. Челябинск
}

\begin{abstract}
На сегодняшний день актуальна тема здорового питания. Для расширения ассортимента продукции, которая позволит ликвидировать дефицит незаменимых пищевых веществ, используются новые виды функционального сырья, которые направлены на коррекцию химического состава пищевых продуктов. Исследовано влияние льняного жмыха в рецептуре соуса красного основного на обогащение соуса минеральными веществами, витаминами, пищевыми волокнами и незаменимыми аминокислотами. При разработке соусов были исследованы физико-химические, витаминно-минеральные, органолептические свойства ингредиента и его процентное содержание. Было обращено внимание на свойство клетчатки, которая поглощает вредные вещества и токсины и выводит их из организма. Клетчатка замедляет усвоение жиров и углеводов и снижает уровень холестерина. В составе льняного жмыха были обнаружены полиненасыщенные кислоты (Омега-3 и Омега-6). Они вынуждают насыщенные жиры, поступающие с пищей животного происхождения, покидать организм. При этом снижается холестерин, и уходят излишки веса. Жмых льна вносили вместе с пшеничной мукой в количестве 5 и $10 \%$. Установлено, что использование жмыха льна более $10 \%$ снижает органолептические показатели продукции - ухудшается внешний вид, вкусовые и ароматические свойства. При добавлении жмыха льна менее 5 \% - обогащение соуса незначительное, внешний вид, вкусовые и ароматические свойства не меняются. Опытный образец с добавлением жмыха льна $5 \%$ не решает поставленную задачу. А опытный образец с добавлением жмыха льна $10 \%$ обеспечивает продукт достаточным количеством пищевых волокон и количеством незаменимых аминокислот. Также улучшаются структурно-реологические, органолептические свойства готового продукта, повышается пищевая и биологическая ценность. Оптимальная дозировка добавки составила $10 \%$.
\end{abstract}

Ключевые слова: соус, биологически активные вещества, полиненасыщенные жирные кислоты, пищевые волокна, источник полезных веществ, диетические свойства.

Наиболее доступный и широко используемый способ ликвидации дефицита и незаменимых пищевых веществ в питании населения и профилактике различных заболеваний - расширение ассортимента продуктов функционального назначения.

Использование новых видов функционального сырья для направленной коррекции химического состава пищевых продуктов требует новых технологических решений, обеспечивающих получение высококачественной, конкурентоспособной продукции.

На сегодняшний день актуальна тема здорового образа жизни, а значит и здорового питания. Не касаясь научных исследований и не проводя научных экспериментов, трудно сказать, какие продукты обладают наиболее важными и необходимыми нашему организму пищевыми веществами [2].

Богатым источником биологически активных веществ являются семена льна, их лечебные свойства известны на протяжении столетий и признаны официальной медициной. Семена льна характеризуются наличием таких пищевых функциональных веществ, как белки с полноценным аминокислотным составом, эссенциальные полиненасыщенные жирные кислоты (ПНЖК) с преобладающим содержанием линоленовой ( $\omega-3)$ кислоты, пищевые волокна. В настоящее время семена льна используются, в основном, в качестве сырья для выработки льняного масла. В то же время количественный и качественный состав белков семян льна свидетельствует о перспективности их применения в качестве источника белка для повышения биологической ценности продуктов питания. Однако белковые продукты из семян льна на территории России не вырабатываются. Семена льна и продукты их переработки (льняной жмых) отличаются по своим технологическим и функциональным показателям. В связи с этим необходимы научные и практические исследования по их внедрению в пищевые технологии [15]. 
Льняной жмых относится к вторичным сырьевым ресурсам. Его получают при отжиме масла на шнековых прессах, методом холодного прессования из предварительно обработанных и очищенных семян льна. Льняной жмых является полноценным источником получения полезных веществ. В нем содержатся полноценные белки, легко усвояемые углеводы, липиды, витамины, минеральные вещества. Также льняной жмых отличается низкой стоимостью, по сравнению с семенами льна [4]. Также клетчатка, находящаяся в льняном жмыхе, усиливает перистальтику кишечника. Она поглощает вредные вещества и токсины и выводит их из организма. Клетчатка замедляет усвоение жиров и углеводов и снижает уровень холестерина. В составе льняного жмыха обнаружены полиненасыщенные кислоты (Омега-3 и Омега-6). Они вынуждают насыщенные жиры, поступающие с пищей животного происхождения, покидать организм. При этом снижается холестерин, и уходят излишки веса. Из этого можно сделать вывод, что именно в тандеме с пищей льняной жмых будет благотворно влиять на организм человека $[13,16]$.

Специфичность химического состава льняного жмыха доказывает целесообразность широкого использования в качестве белково-минеральной добавки с целью повышения пищевой и биологической ценности комбинированных продуктов.

Льняной жмых обладает высокими диетическими свойствами. В распаренном виде льняной жмых образует слизь, такую же, как при варке семени льна и с теми же свойствами. Причем для получения слизи жмых не нужно варить, достаточно просто запарить в достаточном количестве воды, так как экструдированный жмых льна не содержит антипитательных веществ [5]. Льняной жмых имеет высокую энергетическую ценность: в 1 кг жмыха содержится 1,27 к.ед., 13,73 МДж (как в 1,3-1,4 кг овса) и 287 г перевариваемого протеина; а также богатый состав микроэлементов и витаминов [1].

В этом научном исследовании ставится задача обогащения соуса при добавлении пищевой добавки растительного происхождения, которое повысит пищевую ценность продукта. Пищевой добавкой послужит жмых льна [6].

Химический состав, органолептические и физико-химические показатели льняного жмыха будут зависеть от качества семян льна, способов и режимов ядер к прессованию [12]. Химический состав льняного жмыха представлен в табл. 1 и 2.

Таблица 1

Органолептические и физико-химические показатели льняного жмыха

\begin{tabular}{|l|l|}
\hline \multicolumn{1}{|c|}{$\begin{array}{l}\text { Наименование пока- } \\
\text { зателя }\end{array}$} & \multicolumn{1}{|c|}{ Характеристика } \\
\hline Цвет & $\begin{array}{l}\text { От серого до свет- } \\
\text { ло - коричневого }\end{array}$ \\
\hline Запах & $\begin{array}{l}\text { Свойственный } \\
\text { льняному жмыху } \\
\text { без постороннего } \\
\text { запаха }\end{array}$ \\
\hline $\begin{array}{l}\text { Металломагнитная } \\
\text { примесь мг на 1 кг } \\
\text { жмыха }\end{array}$ & Отсутствуют \\
\hline $\begin{array}{l}\text { Прочие посторонние } \\
\text { примеси }\end{array}$ & Отсутствуют \\
\hline
\end{tabular}

Таблица 2

Химический состав льняного жмыха

\begin{tabular}{|l|c|}
\hline \multicolumn{1}{|c|}{ Компоненты } & $\begin{array}{c}\text { Масса г на } 100 \text { г } \\
\text { съедобной части }\end{array}$ \\
\hline Вода & 15 \\
\hline Белок & 26 \\
\hline Жир & 10 \\
\hline Углеводы & 12 \\
\hline Пищевые волокна & 30 \\
\hline Клетчатка & 9,3 \\
\hline
\end{tabular}

Анализ минерального состава жмыха показал, что льняной жмых имеет повышенное содержание калия, фосфора, магния, но имеет низкое содержание кальция. Калия оказалось больше натрия, значит это нужно учитывать при составлении рецептур продуктов с его участием [11].

Минеральный состав в льняном жмыхе представлен в табл. 3.

Количество минералов и витаминов в льняном жмыхе зависят от химического состава льняного семени и от остаточного содержания масла в жмыхе после прессования. При отделении масла меняется содержание основных веществ, минеральных веществ, витаминов в льняном жмыхе [9]. 
Содержание витаминов в льняном жмыхе представлено в табл. 4.

Таблица 3 Минеральный состав льняного жмыха

\begin{tabular}{|c|c|}
\hline Макроэлементы & Содержание, $\Gamma$ \\
\hline $\mathrm{K}$ & 12,4 \\
\hline $\mathrm{Ca}$ & 3,4 \\
\hline $\mathrm{Mg}$ & 4,3 \\
\hline $\mathrm{Na}$ & 3,9 \\
\hline $\mathrm{P}$ & 10 \\
\hline $\mathrm{Mn}$ & 38 \\
\hline $\mathrm{Fe}$ & 197 \\
\hline $\mathrm{Cu}$ & 26,4 \\
\hline $\mathrm{Zn}$ & 69 \\
\hline
\end{tabular}

Содержание витаминов в льняном жмыхе

\begin{tabular}{|l|c|}
\hline \multicolumn{1}{|c|}{ Наименование } & Содержание, г \\
\hline Токоферолы (Е) & 5,8 \\
\hline Тиамин (В1) & 10,2 \\
\hline Рибофлавин (В2) & 4,8 \\
\hline $\begin{array}{l}\text { Пантотеновая кислота } \\
\text { (В3) }\end{array}$ & 9,5 \\
\hline $\begin{array}{l}\text { Никотиновая кислота } \\
\text { (В5) }\end{array}$ & 44 \\
\hline
\end{tabular}

Льняной жмых уникален тем, что после отгонки масла, жиры, остающиеся в льняном жмыхе, обладают полезными свойствами, так же льняной жмых богат содержанием валина и треонина, их значение приближается к максимальному показателю. А лизин, метионин, лейцин являются кислотами, которые лимитируют биологическую ценность белков семени льна $[17,18]$. Содержание незаменимых аминокислот в льняном жмыхе представлено в табл. 5 .

В настоящее время широко известен способ и рецептура приготовления соуса красного основного [10], характеризующийся тем, что нарезанные лук, морковь пассеруют с жиром, добавляют томатное пюре и продолжают пассеровать еще 10-15 минут; просеянную пшеничную муку пассеруют при температуре 150-160 ${ }^{\circ} \mathrm{C}$; охлажденную до 70-80 ${ }^{\circ} \mathrm{C}$ мучную пассеровку разводят теплым бульоном в соотношении 1:4, тщательно размешивают и добавляют пассерованные с томатным пюре овощи и при слабом кипении варят 45-60 минут; в конце варки добавляют соль, сахар, пе- рец черный горошком; соус процеживают, протирая в него готовые овощи, и доводят до кипения [10]. При этом используется следующее соотношение компонентов в граммах на 1000 грамм готового продукта (табл. 6).

Таблица 5 Содержание незаменимых аминокислот в льняном жмыхе

\begin{tabular}{|l|c|}
\hline Наименование & $\begin{array}{c}\text { Содержание незаменимых } \\
\text { аминокислот, г в 1 кг } \\
\text { жмыха }\end{array}$ \\
\hline Валин & 16,7 \\
\hline Изолейцин & 15,8 \\
\hline Лейцин & 19,6 \\
\hline Лизин & 11,1 \\
\hline Метионин & 5,1 \\
\hline Треонин & 12,3 \\
\hline Триптофан & 4,4 \\
\hline Фенилаланин & 13,3 \\
\hline
\end{tabular}

Таблица 6

Раскладка ингредиентов для соуса красного основного

\begin{tabular}{|l|c|c|}
\hline \multicolumn{1}{|c|}{ Ингредиенты } & Брутто & Нетто \\
\hline $\begin{array}{l}\text { Жир животный топленый } \\
\text { пищевой или кулинарный } \\
\text { жир }\end{array}$ & 20 & 20 \\
\hline Мука пшеничная & 50 & 50 \\
\hline Томатное пюре & 100 & 100 \\
\hline Морковь & 100 & 80 \\
\hline Лук репчатый & 24 & 20 \\
\hline Сахар & 15 & 15 \\
\hline Соль & $6-10$ & $6-10$ \\
\hline Перец черный горошком & 0,1 & 0,1 \\
\hline Бульон коричневый & 1000 & 1000 \\
\hline Выход & - & 1000 \\
\hline
\end{tabular}

Недостатком указанного соуса является то, что он беден по содержанию минеральных веществ, витаминов и пищевых волокон.

Технический результат заявляемого эксперимента заключается в повышение пищевой и биологической ценности соуса.

Указанный технический результат достигается за счет того, что в способе приготовления соуса со жмыхом льна, включающего смешивание пассерованных с жиром овощей и томатного пюре, пассерование полученной смеси в течении 10-15 минут, пассерование 
пшеничной муки при температуре $150-160{ }^{\circ} \mathrm{C}$ в течении 5 минут и ее охлаждение до температуры $70-80{ }^{\circ} \mathrm{C}$, гидратирование полученной мучной пассеровки бульоном до соотношения $1: 4$ при температуре бульона $25-30{ }^{\circ} \mathrm{C}$ и добавление к ним пассерованной смеси из пассерованных с жиром овощей и томатного пюpe, совместную варку всех компонентов при температуре $90{ }^{\circ} \mathrm{C}$ в течении 45-60 минут, добавление соли, сахара и перца черного горошком, процеживание сваренной смеси с протиранием в нее готовых овощей, и доведение ее до кипения, согласно эксперименту, пшеничную муку пассеруют, затем вводят льняной жмых, размером частиц 0,06-0,1 мм, не подвергая его тепловой обработке, в соотношении мука пшеничная : жмых льняной $1: 0,1$, при следующем соотношении исходных компонентов в граммах на 1000 грамм готового продукта (табл. 7).

Таблица 7

Раскладка ингредиентов для соуса красного с льняным жмыхом

\begin{tabular}{|l|c|c|}
\hline \multicolumn{1}{|c|}{ Ингредиенты } & Брутто & Нетто \\
\hline $\begin{array}{l}\text { Жир животный топле- } \\
\text { ный пищевой или ку- } \\
\text { линарный жир }\end{array}$ & 20 & 20 \\
\hline Мука пшеничная & 45 & 45 \\
\hline Жмых льняной & $2,5-5$ & $2,5-5$ \\
\hline Томатное пюре & 100 & 100 \\
\hline Морковь & 100 & 80 \\
\hline Лук репчатый & 24 & 20 \\
\hline Сахар & 15 & 15 \\
\hline Соль & $6-10$ & $6-10$ \\
\hline $\begin{array}{l}\text { Перец черный горош- } \\
\text { ком }\end{array}$ & 0,1 & 0,1 \\
\hline Бульон коричневый & 1000 & 1000 \\
\hline Выход & - & 1000 \\
\hline
\end{tabular}

Для пассерования пшеничной муки требуется 5 минут согласно проработкам в лабораторных условиях. Именно это время оптимально для декстринизации структуры крахмального зерна, так как при нагревании до $180{ }^{\circ} \mathrm{C}$ разрушается до $14 \%$ пшеничного крахмала, что позволяет образовать большое количество декстринов, за счет чего снижается способность крахмала к набуханию в горячей воде и клейстеризации [5].

Варка соуса в течение 45-60 минут должна проходить при слабом кипении. Как заяв- лено в [10], оптимальной температурой, подобранной при помощи проработки в лабораторных условиях, является $90^{\circ} \mathrm{C}$.

$\mathrm{B}$ качестве наполнителя используют льняной жмых, предварительно измельченный до размера частиц 0,06-0,1 мм. Использование указанного размера частиц обусловлено максимальным выходом незаменимых аминокислот в соус, его обогащение. Если размер частиц будет менее 0,06 мм, то теряется внешний вид соуса (эстетически не соответствует требованиям, указанным в [10]). Если же размер частиц будет более 0,1 мм, то в этом случае будет происходить меньшее количество выхода незаменимых аминокислот в соус и, тем самым, обогащение соуса будет незначительным $[7,8]$.

Льняной жмых характеризуется высокими пищевыми и вкусовыми достоинствами. В его состав входят незаменимые жирные кислоты (олеиновая, линолевая), которые способствуют лучшей усвояемости питательных веществ организмом. Также в льняном жмыхе много белка, богатого незаменимыми аминокислотами (лизин, метионин, аргинин, валин, тренин), протеина, углеводов, в которых присутствует клетчатка, необходимая для полноценной работы желудочно-кишечного тракта. По содержанию фосфора и кальция, меди, магния, марганца, льняной жмых превосходит соевый аналог [3].

При добавлении в соус красный основной льняного жмыха улучшаются структурнореологические, органолептические свойства готового продукта, повышается его пищевая и биологическая ценность [14].

В лабораторных условиях в качестве проработки были выявлены пределы внесения льняного жмыха, которые можно обосновать следующим образом. Добавление льняного жмыха в количестве 2,5 г от массы муки пшеничной не обеспечивает продукт достаточным количеством пищевых волокон и количеством незаменимых аминокислот. Добавление льняного жмыха в количестве более 5 г от массы муки пшеничной ухудшает органолептические свойства готового продукта, появляется очевидный масляный привкус.

Способ приготовления соуса красного основного осуществляется следующим образом.

\section{Пример 1}

Для приготовления соуса со жмыхом льна морковь и лук нарезали, пассеровали с жиром и смешивали с томатным пюре. Полученную 
смесь пассеровали в течение 10 минут. Пшеничную муку пассеровали при температуре $150{ }^{\circ} \mathrm{C}$ в течение 5 минут, затем добавляли жмых льна, размером частиц 0,06 мм, не подвергая его тепловой обработке, охлаждали до температуры $70{ }^{\circ} \mathrm{C}$. Далее добавляли в полученную мучную пассеровку со жмыхом льна бульон до соотношения мучная пассеровка: бульон 1:4 при температуре бульона $30{ }^{\circ} \mathrm{C}$ и смесь из пассерованных с жиром овощей и томатного пюре. Далее осуществляли совместную варку всех компонентов при температуре $90{ }^{\circ} \mathrm{C}$ в течение 45 минут, добавили соль, сахар и перец черный горошком. Полученную смесь процеживали с протиранием в нее готовых овощей, и довели ее до кипения. При этом исходные компоненты были взяты в следующем количестве в граммах на 1000 грамм готового продукта (табл. 8).

Таблица 8

Раскладка ингредиентов по рецептуре 1

\begin{tabular}{|l|c|c|}
\hline \multicolumn{1}{|c|}{ Ингредиенты } & Брутто & Нетто \\
\hline Морковь & 100 & 80 \\
\hline Лук & 24 & 20 \\
\hline $\begin{array}{l}\text { Жир животный топле- } \\
\text { ный пищевой или ку- } \\
\text { линарный жир }\end{array}$ & 20 & 20 \\
\hline Томатное пюре & 100 & 100 \\
\hline Мука пшеничная & 45 & 45 \\
\hline Жмых льняной & 5 & 5 \\
\hline Соль & 6 & 6 \\
\hline Сахар & 15 & 15 \\
\hline $\begin{array}{l}\text { Перец черный горош- } \\
\text { ком }\end{array}$ & 0,1 & 0,1 \\
\hline Бульон коричневый & 1000 & 1000 \\
\hline Выход & - & 1000 \\
\hline
\end{tabular}

\section{Пример 2}

Для приготовления соуса со жмыхом льна морковь и лук нарезали, пассеровали с жиром и смешивали с томатным пюре. Полученную смесь пассеровали в течении 10 минут. Пшеничную муку пассеровали при температуре $150{ }^{\circ} \mathrm{C}$ в течение 5 минут, затем добавляли жмых льна, размером частиц 0,05 мм, не подвергая его тепловой обработке, охлаждали до температуры $70{ }^{\circ} \mathrm{C}$. Далее добавляли в полученную мучную пассеровку со жмыхом льна бульон до соотношения мучная пассеровка: бульон 1:4 при температуре бульона $30{ }^{\circ} \mathrm{C}$ и смесь из пассерованных с жиром овощей и томатного пюре. Далее осуществляли совместную варку всех компонентов при температуре $90^{\circ} \mathrm{C}$ в течении 45 минут, добавили соль, сахар и перец черный горошком. Полученную смесь процеживали с протиранием в нее готовых овощей, и довели ее до кипения [19]. При этом исходные компоненты были взяты в следующем количестве в г на 1000 г готового продукта (табл. 9).

Таблица 9

Раскладка ингредиентов по рецептуре 2

\begin{tabular}{|l|c|c|}
\hline \multicolumn{1}{|c|}{ Ингредиенты } & Брутто & Нетто \\
\hline Морковь & 100 & 80 \\
\hline Лук & 24 & 20 \\
\hline $\begin{array}{l}\text { Жир животный топленый } \\
\text { пищевой или кулинарный } \\
\text { жир }\end{array}$ & 20 & 20 \\
\hline Томатное пюре & 100 & 100 \\
\hline Мука пшеничная & 47,5 & 47,5 \\
\hline Жмых льняной & 2,5 & 2,5 \\
\hline Соль & 6 & 6 \\
\hline Сахар & 15 & 15 \\
\hline Перец черный горошком & 0,1 & 0,1 \\
\hline Бульон коричневый & 1000 & 1000 \\
\hline Выход & - & 1000 \\
\hline
\end{tabular}

Результатом исследования является обогащение соуса пищевыми волокнами и повышение пищевой и биологической ценности готового продукта. Пищевая ценность жмыха льна указывает на возможность использования льняного жмыха при выборе соусов максимального использования. Льняной жмых имеет высокую энергетическую ценность, что позволяет обогатить соус пищевыми волокнами, пищевой и биологической ценностью (табл. 10).

Дегустационной оценкой установлено, что соус красный основной, полученный по примеру 1 , является более приятным на вкус и аромат, стал более богат по содержанию минеральных веществ, витаминов и пищевых волокон.

\section{Лuтература}

1. Аксенова, Л. А. Основные тенденции развития мирового сельского хозяйства / Л.А. Аксенова // География в школе. - 2008. № 1. - C. 3-9.

2. Богатырев, А.Н. Здоровая пища - здоровая нация / А.Н. Богатырев // Пищевая промышленность. - 2001. - № 8. - С. 68-69. 
Органолептические показатели модельных образцов соусов

Таблица 10 с пищевой добавкой растительного происхождения

\begin{tabular}{|c|c|c|}
\hline \multirow{2}{*}{$\begin{array}{l}\text { Наименование } \\
\text { показателей }\end{array}$} & \multicolumn{2}{|c|}{ Характеристика образца соуса } \\
\hline & Пример 1 & Пример 2 \\
\hline \multicolumn{3}{|c|}{ Срок хранения при температуре $5^{\circ} \mathrm{C}$ в течение 10 суток } \\
\hline Цвет & $\begin{array}{c}\text { Однородный по всей массе, ка- } \\
\text { рамельный }\end{array}$ & $\begin{array}{c}\text { Однородный по всей массе, } \\
\text { светло-коричневый }\end{array}$ \\
\hline Вкус & $\begin{array}{c}\text { Сбалансированный, насыщен- } \\
\text { ный, приятный }\end{array}$ & Сбалансированный, приятный \\
\hline Запах & $\begin{array}{c}\text { Гармоничный, овощной, с рас- } \\
\text { тительным компонентом }\end{array}$ & Гармоничный, овощной \\
\hline Консистенция & \multicolumn{2}{|c|}{ Однородный продукт, умеренно густой, текучий } \\
\hline
\end{tabular}

3. Волкова, Н.Н. Ингредиентный составоснова получения высококачественных пищевых продуктов / Н.Н. Волкова // Хранение и переработка сельскохозяйственного сырья. 2008. - № 11. - C. 30.

4. Воробьева, А.В. Влияние жирнокислотного состава растительных масел на функциональные свойства эмульсионных продуктов / А.В. Воробьева, Н.Н. Волкова // Сборник трудов международной научной конференции (посвященный 55-летию основания МГУТУ). 2008. - Bbin. 13, m. 5. - C. 33-35.

5. Воробьева, А.В. Современные тендениии создания эмульсионных продуктов для здорового питания / А.В. Воробьева, Н.Н. Волкова // Пищевая промышленность. - 2008. - № 11. - C. 72.

6. Воронова, Н.С. Исследование состава льняного жмыха как нового ингредиента в производстве молочных продуктов / Н.С. Воронова, Л.С. Бередина // Современные тенденции технических наук: материаль IV междунар. науч. конф. (2. Казань, октябрь 2015 г.). - Казань: Бук, 2015. - С. 93-96.

7. ГОСТ 10974-95. Жмых льняной. Технические условия.

8. ГОСТ 23676-79. Весы для статического взвешивания, предель взвешивания. Метрологические параметры.

9. Донская, Г.А. Пищевые волокна - стимуляторы роста полезной микрофлоры организма человека / Г.А. Донская // Пищевые ингредиенты: сырье и добавки. - 2004. - № 1. C. 21.
10. Здобнов, А.И. Сборник рецептур блюд и кулинарных изделий: для предприятий общественного питания / А.И. Здобнов, В.А. Цыганенко - М.: «ИКТЦ «ЛАДА»; Киев: «Издательство «Арий», 2006. - 680 с.

11. Иванова, Л.А. Пищевая биотехнология. Кн. 2: Переработка растительного сырья / Л.А. Иванова, Л.И. Войно, И.С. Иванова. - М.: Колосс, 2008. - 472 c.

12. Кайтев, В.Г. Анализ макроэкономических показателей развития пищевой и перерабатывающей промышленности Российской Федерации за 1995-2006 г2. / В.Г. Кайшев // Пищевая промышленность. - 2007. - № 5. C. 42-45.

13. Лекарственное сырье растительного и животного происхождения. Фармакогнозия: учебное пособие / под ред. Г.П. Яковлева. - СПб.: СпеиЛит, 2006. -845 c.

14. Паменко, Л.П. Применение семян масличного льна в мучных кондитерских изделиях / Л.П. Паменко, Л.А. Коваль, В.Л. Пащенко // Современные наукоемкие технологии. - 2006. - № 6. - C. 95-96.

15. Современная торговля, теория, практика, современное развитие: материаль Первой международной инновачионной научно-практической конференции, 12 марта 2012 2. [Электронный ресурс] / Под общей ред. С. Колобова. М.: - Изд-во Московского гуманитарного университета, 2012. - 1725 c.

16. Тамкович, С.К. Технология формирования качества эмульсионных нектаров на основе тыквы (Cucurbita Melon) с добавлением сока ягод жимолости, лимонника, рябины, 
шиповника / С.К. Тамкович и др. // Пищевая промышленность. - 2005. - № 7. - С. 77.

17. Adhikari C, Proctor A., Blyholder G.D. Diffuse-reflectancc fourier-ransform infrared; spectroscopy of vegetable oil txiglycpecride adsorption on silicic acid // J: Amer. Oil Chem. Soc. 1994. - V. 71, iss. 6. - P. 589-594.
18. Eidhin, DMN. Polyphenol Oxydase from Apple: Purification strategies and characterization / DMN Eidhin, E. Murphy, D.O. Beirne // J. Food Science: Food Chemistry and Toxicology. 2006. - Vol. 71, № 1. - P. 51-58.

19. Hristova, J. Biochemical peculiarities of octopioid and iploid Triticale forms /I PflanzcnzDcht. - 2006. - № 73. - S. 71-78.

Тошев Абдували Джабарович. Профессор, доктор технических наук, заведующий кафедрой технологии продукции общественного питания Института экономики, торговли и технологий, Южно-Уральский государственный университет (г. Челябинск).

Журавлева Наталья Дмитриевна. Ассистент, соискатель научной степени кафедры технологии продукции общественного питания Института экономики, торговли и технологий, Южно-Уральский государственный университет (г. Челябинск), barsiksofa@mail.ru

Поступила в редакцию 22 апреля 20162.

DOI: $10.14529 /$ food 160212

\title{
DEVELOPMENT OF THE TECHNOLOGY OF SAUCES WITH PHYTOGENICS WITH HIGH NUTRITIONAL QUALITIES
}

\author{
A.D. Toshev, N.D. Zhuravleva \\ South Ural State University, Chelyabinsk, Russian Federation
}

\begin{abstract}
Today the issue on healthy nutrition is topical. To expand the range of products, which will allow to eliminate the deficit of essential nutrients, new types of functional materials aimed at correcting the chemical composition of foodstuffs are used. The effect of linseed cake in the recipe of the main red sauce on its enrichment with minerals, vitamins, dietary fibers and essential amino acids is studied. During the process of development of the sauces the physicochemical, vitamin and mineral, and organoleptic properties of the ingredient and its percentage are investigated. The attention is paid to the property of fiber, which absorbs harmful substances and toxins, and removes them from the body. Fiber slows down the absorption of fats and carbohydrates, and reduces cholesterol. Polyunsaturated fatty acids (Omega-3 and Omega-6) are found in the content of linseed cake. They force saturated fats that come with animal-based food to leave the body. At the same time the cholesterol is reduced, and excess weight is lost. The flaxseed cake is added together with wheat flour in an amount of 5 and $10 \%$. It is found out that the use of more than $10 \%$ of flaxseed cake reduces the organoleptic properties of the product - the appearance, taste and aromatic properties are deteriorated. When adding less than $5 \%$ of flaxseed cake, the enrichment of the sauce is insufficient; appearance, flavor and aromatic properties are not changed. The prototype with $5 \%$ flaxseed cake additive does not solve the problem. And the prototype with $10 \%$ of flaxseed cake additive provides the product with a sufficient amount of dietary fibers and essential amino acids. The structural and rheological, organoleptic properties of the finished product are also improved, food and biological value is increased. The optimal dosage of the additive is $10 \%$.

Keywords: sauce, biologically active substances, polyunsaturated fatty acids, dietary fibers, source of nutrients, dietary properties.
\end{abstract}

\section{References}

1. Aksenova L.A. [Major trends in the development of world agriculture]. Geografiya v shkole [Geography at school], 2008, no. 1, pp. 3-9. (in Russ.)

2. Bogatyrev A.N. [Healthy Food - Healthy Nation]. Pishchevaya promyshlennost' [Food Industry], 2001, no. 8, pp. 68-69. (in Russ.)

3. Volkova N.N. [Ingredient composition - the basis of producing high-quality food products]. Khranenie i pererabotka sel'skokhozyaystvennogo syr'ya [Storage and processing of agricultural raw materials], 2008, no. 11, p. 30. (in Russ.) 
4. Vorob'eva A.V., Volkova N.N. The influence of the fatty acid composition of vegetable oils on the functional properties of the emulsion products. Sbornik trudov mezhdunarodnoy nauchnoy konferentsii (posvyashchennyy 55-letiyu osnovaniya MGUTU) [Collection of research papers of the International Scientific Conference (dedicated to the 55th anniversary of the MSUTM)], 2008, iss. 13, vol. 5, pp. 33-35. (in Russ.)

5. Vorob'eva A.V., Volkova N.N. Current trends of creating emulsion products for a healthy nutrition. Pishchevaya promyshlennost' [Food industry], 2008, no. 11, p. 72. (in Russ.)

6. Voronova N.S., Beredina L.S. [Investigation of the composition of flaxseed cake as a new ingredient in the production of dairy products]. Sovremennye tendentsii tekhnicheskikh nauk: materialy IV mezhdunar. nauch. konf. (g. Ka$z a n^{\prime}$, oktyabr' 2015 g.) [Modern trends in technical sciences: materials of the IV International Scientific Conference (the city of Kazan, October 2015)]. Kazan', 2015, pp. 93-96. (in Russ.)

7. GOST 10974-95. Zhmykh l'nyanoy. Tekhnicheskie usloviya [State Standard 10974-95. Linseed cake. Specifications].

8. GOST 23676-79. Vesy dlya staticheskogo vzveshivaniya, predely vzveshivaniya. Metrologicheskie parametry [State Standard 23676-79. Balance for static weighing, weighing limits. The metrological parameters].

9. Donskaya G.A. [Dietary fiber - stimulators for the growth of beneficial microflora of the human body]. Pishchevye ingredienty: syr'e i dobavki [Food ingredients: raw materials and additives], 2004, no. 1, p. 21. (in Russ.)

10. Zdobnov A.I., Tsyganenko V.A. Sbornik retseptur blyud i kulinarnykh izdeliy: dlya predpriyatiy obshchestvennogo pitaniya [Collection of recipes of dishes and culinary products: For catering enterprises]. Moscow, Kiev, 2006. $680 \mathrm{p}$.

11. Ivanova L.A., Voyno L.I., Ivanova I.S. Pishchevaya biotekhnologiya. Kn. 2: Pererabotka rastitel'nogo syr'ya [Food Biotechnology. Vol. 2, Vegetable raw material processing]. Moscow, Koloss Publ., 2008. 472 p.

12. Kayshev V.G. [The analysis of macroeconomic indicators of the development of food and processing industry of the Russian Federation over the period of 1995-2006]. Pishchevaya promyshlennost' [Food industry], 2007, no. 5, pp. 42-45. (in Russ.)

13. Yakovlev G.P. (Ed.) Lekarstvennoe syr'e rastitel'nogo i zhivotnogo proiskhozhdeniya. Farmakognoziya [Medicinal raw materials of vegetable and animal origin. Pharmacognosy]. St. Petersburg, 2006. 845 p.

14. Pashchenko L.P., Koval' L.A., Pashchenko V.L. [The use of oilseed flax flour in confectionery]. Sovremennye naukoemkie tekhnologii [Modern high technologies], 2006, no. 6, pp. 95-96. (in Russ.)

15. Kolobov S. (Ed.) Sovremennaya torgovlya, teoriya, praktika, sovremennoe razvitie: materialy Pervoy mezhdunarodnoy innovatsionnoy nauchno-prakticheskoy konferentsii, 12 marta $2012 \mathrm{~g}$. [Materials of the First International Innovation Scientific and Practical Conference, March 12, 2012]. Moscow, 2012. 1725 p.

16. Tamkovich C.K. et al. Technology of formation of the quality of emulsion nectars based on pumpkin (Cucurbita Melon) with the addition of juice of honeysuckle berries, lemongrass, rowan, and rose. Pishchevaya promyshlennost [Food industry], 2005, no. 7, p. 77. (in Russ.)

17. Adhikari C, Proctor A., Blyholder G.D. Diffuse-reflectancc fourier-ransform infrared; spectroscopy of vegetable oil txiglycpecride adsorption on silicic acid. J: Amer. Oil Chem. Soc. 1994, vol. 71, iss. 6, pp. 589-594. DOI: $10.1007 / \mathrm{bf} 02540584$

18. Eidhin, DMN., Murphy E., Beirne D.O. Polyphenol Oxydase from Apple: Purification strategies and characterization. J. Food Science: Food Chemistry and Toxicology, 2006, vol. 71, pp. 51-58. DOI: 10.1111/j.13652621.2006.tb12388.x

19. Hristova J. Biochemical peculiarities of octopioid and iploid Triticale forms // PflanzcnzDcht, 2006, no. 73, pp. $71-78$.

Abduvali D. Toshev. Professor, Doctor of Sciences (Engineering), Head of the Department of Technology of Catering Products of the Institute of Economics, Trade and Technology, South Ural State University, Chelyabinsk.

Natalia D. Zhuravleva. Assistant, postgraduate degree seeker of the Department of Technology of Catering Products of the Institute of Economics, Trade and Technology, South Ural State University, Chelyabinsk, barsiksofa@mail.ru

Received 22 April 2016

\section{ОБРАЗЕЦ ЦИТИРОВАНИЯ}

Тошев, А.Д. Разработка технологии соусов с добавкой растительного происхождения с повышенной пищевой ценностью / А.Д. Тошев, Н.Д. Журавлева // Вестник ЮУрГУ. Серия «Пищевые и биотехнологии». - 2016. T. 4, № 2. - C. 94-101. DOI: 10.14529/food 160212

\section{FOR CITATION}

Toshev A.D., Zhuravleva N.D. Development of the Technology of Sauces with Phytogenics with High Nutritional Qualities. Bulletin of the South Ural State University. Ser. Food and Biotechnology, 2016, vol. 4, no. 2, pp. 94-101. (in Russ.) DOI: 10.14529/food 160212 